\title{
The impact of ball recovery type, location of ball recovery and duration of possession on the outcomes of possessions in the English Premier League and the Spanish La Liga
}

\section{Daniel Cooper \& Craig Pulling}

To cite this article: Daniel Cooper \& Craig Pulling (2020): The impact of ball recovery type, location of ball recovery and duration of possession on the outcomes of possessions in the English Premier League and the Spanish La Liga, Science and Medicine in Football, DOI: 10.1080/24733938.2020.1722319

To link to this article: https://doi.org/10.1080/24733938.2020.1722319

\section{冓 Accepted author version posted online: 24} Jan 2020.

Published online: 27 Jan 2020.

Submit your article to this journal

\section{Цll Article views: 85}

a)

View related articles

View Crossmark data $₫$ 


\title{
The impact of ball recovery type, location of ball recovery and duration of possession on the outcomes of possessions in the English Premier League and the Spanish La Liga
}

\author{
Daniel Cooper (D) and Craig Pulling (D) \\ Chichester Institute of Sport, University of Chichester, Chichester, UK
}

\begin{abstract}
Objective: The aim of this study was to explore the impact of the ball recovery type, location of ball recovery and the duration of the possession on the outcomes of possessions in both the EPL and the Spanish La Liga.

Methods: In total, 4971 possessions were observed across 20 matches from the 2017/2018 season of both the EPL $(n=2469)$ and La Liga $(n=2502)$. Ball recovery was analysed across four zones, supplemented by five types of ball recovery (interception, tackle, goalkeeper save, set-play and turnover) and three different possession duration categories ( $<5$ seconds, 5-12 seconds and $>12$ seconds). Each of these were analysed according to five different attacking outcomes.

Results: La Liga teams scored relatively more goals when recovering possession through a tackle $(2.5 \%$ of tackles led to a goal). EPL teams scored relatively more goals and took more shots after turnovers ( $2.0 \%$ of turnovers led to a goal and $14.6 \%$ of turnovers led to a shot). EPL teams are more likely to score a goal or create a shooting opportunity when utilising shorter possessions ( $<5$ seconds), whereas La Liga teams are more likely to score a goal after utilising longer possessions ( $>12$ seconds).
\end{abstract}

\section{ARTICLE HISTORY}

Accepted 21 January 2020

\section{KEYWORDS}

Performance analysis; football; coaching; tactics; strategy

\section{Introduction}

Ball possession within soccer has received plenty of attention in performance analysis research (Kempe et al. 2014). Ball possession begins when a team regains possession, with clear control over the ball, to be able to convey guidance upon its path, and it ends when a pre-determined outcome occurs (Pollard and Reep 1997). The majority of current research focuses primarily on what teams do when they are in possession of the ball (Mackenzie and Cushion 2013), such as goals scored (Wright et al. 2011; Hughes and Lovell 2019), score-box possessions (defined as an entry into the penalty box with high degree of control over the ball) (Lago-Ballesteros et al. 2012) and goal scoring opportunities (Tenga et al. 2010a; Gonzalez-Rodenas et al. 2015). This approach fails to acknowledge defensive conduct contributing towards ending attacks. Losing possession has been described as the biggest gauge of unsuccessful performance, and is therefore an important factor that warrants further research (Shafizadeh et al. 2012).

Ball recoveries are of critical importance as they signal the completion of the defensive stage and the initiation of an attack (Santos et al. 2017). Despite its importance, ball recovery patterns are under-researched (Barreira et al. 2014a). Existing research commonly agrees that possession is most commonly recovered in the defensive zones (Almeida et al. 2014; Barreira et al. 2014b). Barreira et al. (2014b) investigated the ball recovery patterns of the semi-finalist teams in the 2010 FIFA World Cup and found that teams recovered the ball significantly more in the central defensive zone and the central mid-defensive zone than any other zones on the pitch. Previous research has also highlighted that possessions that started from attacking zones are more likely to result in positive attacking outcomes, such as goals, shots, goal scoring opportunities and set-plays won (Gonzalez-Rodenas et al. 2015; Sarmento et al. 2018). Specifically, Hughes and Lovell (2019) investigated all the knockout stage games of the 2014-2015 Champions League and stated that ball recoveries in the offensive zone (defined as the most advanced transverse attacking quarter of the pitch) created a scoring opportunity (goals, shots, crosses and set pieces) $49.45 \%$ of the time with $7.69 \%$ leading to goals. It was reported that teams were almost 7 times more likely to create a scoring opportunity from ball recoveries initiated in the offensive zone than the defensive zone (the least advanced transverse attacking quarter of the pitch), and over 11 times more likely to score a goal. Previous research has indicated that interceptions are the most commonly used ball recovery type (Almeida et al. 2014; Sarmento et al. 2018; Hughes and Lovell 2019). The research findings are currently equivocal on the type of ball recovery which leads to the most positive attacking outcomes with researchers divided between tackles (Barreira et al. 2014b; Hughes and Lovell 2019) and set-plays (Armatas and Yiannakos 2010; Gonzalez-Rodenas et al. 2015).

After regaining the ball, the time duration of the possession is a critically important factor of the build-up play (Carling et al. 2005). The duration for which a team maintains possession could be explained by their style of play (Casal et al. 2017), and the performance and tactics of the opposition (Lago-Peñas and Dellal 2010). Sarmento et al. (2018) stressed that further analysis into possession duration is necessary, in order to

CONTACT Craig Pulling c.pulling@chi.ac.uk Chichester Institute of Sport, University of Chichester, Bishop Otter Campus, College Lane, Chichester P019 6PE UK 
contribute greater insight into general team performance. Research has not clearly identified the most commonly used possession duration, however many studies have concluded that the possessions of longer duration are more likely to result in positive attacking outcomes, such as goals and score-box possessions (Tenga and Sigmundstad 2011; Lago-Ballesteros et al. 2012).

Previous research has identified the importance of ball recovery, however there is still a need to address and explore a range of variables that impact on ball recoveries and the subsequent possession. The aim of this study was to explore the impact of the ball recovery type, location of ball recovery and the duration of the possession on the outcomes of possessions in both the EPL and the Spanish La Liga.

\section{Method}

A total of 4971 possessions were analysed through systematic observation by the first author. These possessions were sampled from 20 men's professional football matches from the 2017/2018 season, consisting of 10 matches from the Spanish La Liga and 10 matches from the EPL. These matches included 18 of the $20 \mathrm{EPL}$ teams competing within the 2017/ 2018 season, and 17 of the 20 La Liga teams competing within the 2017/2018 season to ensure the sample is representative of the whole league (Sarmento et al. 2018). This study comprises of matches within varying stages of the season, with matches in nine out of the 10 active months of both the EPL and La Liga being included. The matches were observed post-event after being sourced from public television airings by Sky Sports and BT Sport in the United Kingdom.

An observation instrument was developed and created using Microsoft Office Excel (Microsoft Corporation, Excel 2016, Redmond, Washington). The observation instrument enabled the observer to record the ball recovery zone; ball recovery type; the duration of the possession and the possession outcomes. Prior to any data being collected, a pilot study was undertaken to assess the observation instrument. Half of an EPL match from the 2017/2018 was observed and 119 possessions were analysed. All variables were analysed during the pilot test and it revealed that the possession outcomes of 'goalkeeper claim - defence', and 'misplaced pass/ touch' needed to be included within the observation instrument.

The location in which possession was gained ('ball recovery zone') was manually coded according to 12 specific pitch zones, labelled as the 'left defence', 'centre defence', 'right defence', 'left pre-defence', 'centre pre-defence', 'right pre-defence', 'left pre-attack', 'centre pre-attack', 'right pre-attack', 'left attack', 'centre attack', and 'right attack' (Eldridge et al. 2013; Barreira et al. 2014b) (Figure 1).

Possession was deemed to be recovered after a team had a high degree of control over the ball (Lago-Ballesteros et al. 2012). The method the team used to gain possession was classified according to five different ball recovery types: 'interception'; 'tackle'; 'goalkeeper save'; 'set-play'; and 'turnover' (Table 1).

Once the team had recovered the ball, the duration of the possession was recorded in seconds(s) and assigned to one of 13 categories. The following categories were: '0s-0.99s'; '1s1.99s'; '2s-2.99s'; '3s-3.99s'; '4s-4.99s'; '5s-5.99s'; '6s-6.99s'; '7s7.99s'; '8s-8.99s'; '9s-9.99s'; '10s-10.99s'; '11s-11.99s'; and ' $\geq 12 s^{\prime}$ (Smith et al. 2013). Time duration was recorded using the stopwatch application on a Samsung Galaxy Note 8 smartphone. The main outcome of every possession was recorded with 15 potential outcomes identified for the data collection progress: 'goal (1)'; 'shot on target (2)'; 'shot off target (3)'; 'shot blocked (4)'; 'free kick won (5)'; 'penalty won (6)'; 'corner won (7)'; 'misplaced pass/touch (8)'; 'offside (9)'; 'clearance (10)'; 'foul committed (11)'; 'interception - defence (12)'; 'tackle - defence (13)'; 'clearance - defence (14)'; and 'goalkeeper claim - defence (15)'. The operational definitions of these outcomes are presented in Table 2.

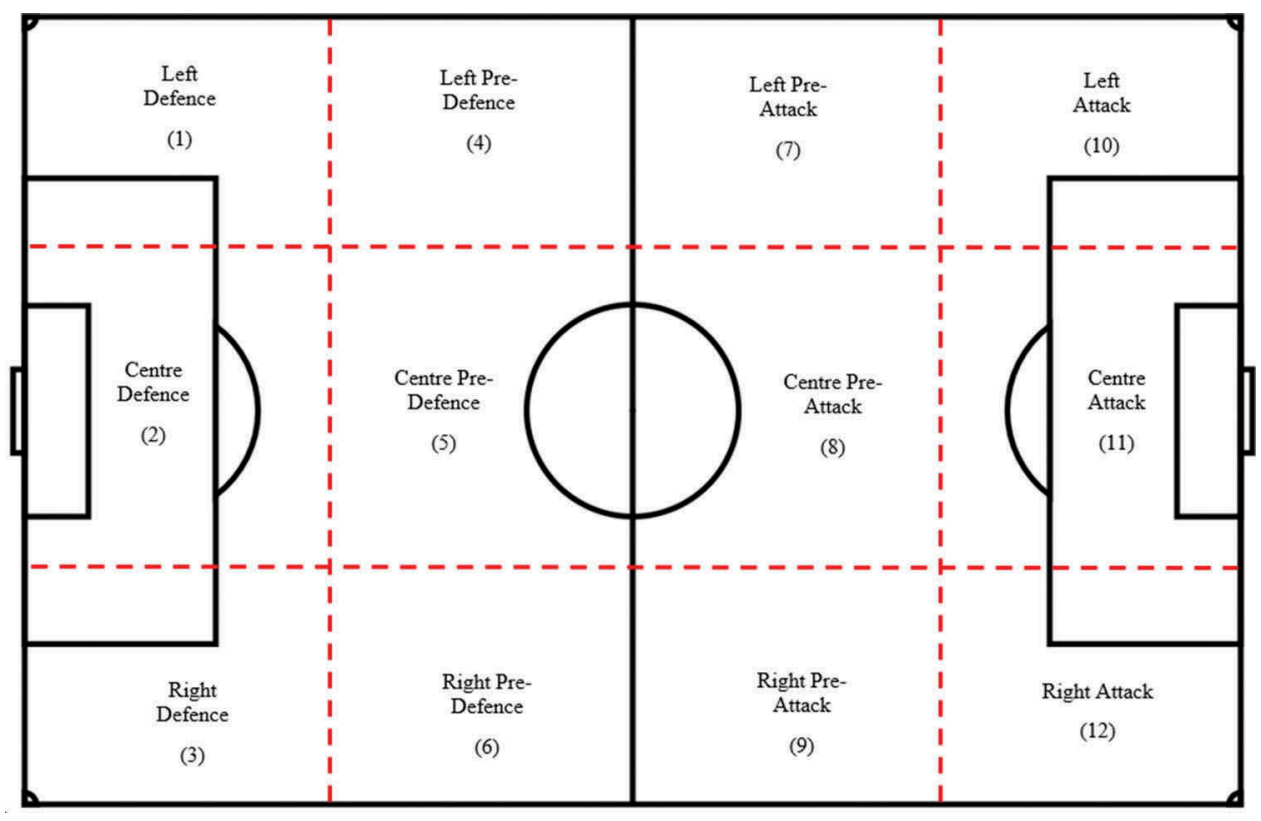

Figure 1. Ball recovery zones (Eldridge et al. 2013; Barreira et al. 2014b). 
Table 1. Operational definitions for ball recovery types.

\begin{tabular}{|c|c|}
\hline Term & Definition \\
\hline Interception & $\begin{array}{l}\text { Reading the game and moving towards the ball, to cut off the } \\
\text { intended pass, and recover the ball, resulting in controlled } \\
\text { possession (Rowlinson and O'Donoghue 2008). }\end{array}$ \\
\hline Tackle & $\begin{array}{l}\text { Dispossessing an opposition player through a physical } \\
\text { challenge or defensive pressure, resulting in controlled } \\
\text { possession (Rowlinson and O'Donoghue 2008). }\end{array}$ \\
\hline $\begin{array}{l}\text { Goalkeeper } \\
\text { save }\end{array}$ & $\begin{array}{l}\text { The goalkeeper stops an attacker from scoring, following a shot, } \\
\text { resulting in controlled possession (Barreira et al. 2014b). }\end{array}$ \\
\hline Set-play & $\begin{array}{l}\text { Static conditions used to return the ball to open play, derived } \\
\text { from misses, fouls and goals, resulting in controlled } \\
\text { possession (Barreira et al. 2014b). }\end{array}$ \\
\hline Turnover & $\begin{array}{l}\text { Gathering a lost ball in open play, after a deflection, rebound, or } \\
\text { a mistake from the opposition, resulting in controlled } \\
\text { possession (Gómez et al. 2012; Wright et al. 2011). }\end{array}$ \\
\hline
\end{tabular}

Table 2. Operational definitions for possession outcomes.

\begin{tabular}{|c|c|}
\hline Term & Definition \\
\hline Goal & $\begin{array}{l}\text { The ball moved over the goal-line, and the referee awarded } \\
\text { a goal (Pulling et al. 2013). }\end{array}$ \\
\hline Shot on target & $\begin{array}{l}\text { An obvious attempt to score which would result in a goal if } \\
\text { not obstructed (Bateman 2012; OPTA 2012). }\end{array}$ \\
\hline Shot off target & $\begin{array}{l}\text { An attempt to score which would not result in a goal if not } \\
\text { obstructed (Bateman 2012; OPTA 2012). }\end{array}$ \\
\hline Blocked shot & $\begin{array}{l}\text { Obstruction of a shot directed on target by the defence } \\
\text { (Bateman 2012; OPTA 2012). }\end{array}$ \\
\hline Free kick & $\begin{array}{l}\text { A set-play awarded after a foul from the opposition, outside } \\
\text { the penalty area (Bateman 2012; OPTA 2012). }\end{array}$ \\
\hline Penalty kick & $\begin{array}{l}\text { A set-play awarded after a foul from the opposition, inside } \\
\text { the penalty area (Bateman 2012; OPTA 2012). }\end{array}$ \\
\hline Corner kick & $\begin{array}{l}\text { Awarded after the ball leaves the field of play behind the } \\
\text { goal line after touching a defender last (Bateman 2012; } \\
\text { OPTA 2012). }\end{array}$ \\
\hline $\begin{array}{l}\text { Misplaced pass/ } \\
\text { touch }\end{array}$ & $\begin{array}{l}\text { Losing possession of the ball as a result of a mistake or poor } \\
\text { control (Bateman 2012; OPTA 2012). }\end{array}$ \\
\hline Offside & $\begin{array}{l}\text { An attacker is nearer the opponents' goal than the second- } \\
\text { to-last opponent when receiving the ball, resulting in } \\
\text { a free kick (Bateman 2012; OPTA 2012). }\end{array}$ \\
\hline Clearance & $\begin{array}{l}\text { Attempt to get the ball out of a dangerous area, whilst } \\
\text { under some kind of opposition pressure (Rowlinson and } \\
\text { O'Donoghue 2008). }\end{array}$ \\
\hline Foul & $\begin{array}{l}\text { An infringement of the rules by the attacking side, deemed } \\
\text { to be foul play by the referee, resulting in a set-play } \\
\text { (Bateman 2012; OPTA 2012). }\end{array}$ \\
\hline $\begin{array}{l}\text { Interception - } \\
\text { defence }\end{array}$ & $\begin{array}{l}\text { Reading the game, moving towards the ball, to cut off the } \\
\text { intended pass, and regain possession (Rowlinson and } \\
\text { O'Donoghue 2008). }\end{array}$ \\
\hline Tackle - defence & $\begin{array}{l}\text { Dispossessing an opposition player through a physical } \\
\text { challenge or defensive pressure (Rowlinson and } \\
\text { O'Donoghue 2008). }\end{array}$ \\
\hline $\begin{array}{l}\text { Clearance - } \\
\text { defence }\end{array}$ & $\begin{array}{l}\text { The defender attempts to get the ball out of a dangerous } \\
\text { area, whilst under some kind of opposition pressure } \\
\text { (Rowlinson and O'Donoghue 2008). }\end{array}$ \\
\hline $\begin{array}{l}\text { Goalkeeper } \\
\text { claim }\end{array}$ & $\begin{array}{l}\text { The goalkeeper catches a cross or a pass into the penalty } \\
\text { area, where there is some kind of opposition pressure } \\
\text { (Bateman 2012; OPTA 2012). }\end{array}$ \\
\hline
\end{tabular}

\section{Reliability}

Inter-observer and intra-observer reliability analyses were carried out to assess the objectivity and reliability of the data respectively. An analyst who had three year's experience of analysing soccer and was not part of the research team was selected for the inter-observer reliability analysis. One week prior to the reliability testing the analyst was provided with the observation instrument. On the day of the testing, the analyst was shown how to code using the observation instrument and was given access to the stopwatch application on a Samsung Galaxy Note 8 smartphone. Once the analyst had confirmed that they were confident
Table 3. Reliability tests and Kappa statistics.

\begin{tabular}{llcc}
\hline Reliability Test & \multicolumn{1}{c}{ Variable } & $\begin{array}{c}\text { Kappa } \\
\text { Value }\end{array}$ & $\begin{array}{c}\text { Strength of } \\
\text { Agreement (Altman } \\
1991)\end{array}$ \\
\hline Inter-operator & Ball Recovery Zone & 0.90 & Very good \\
Inter-operator & Ball Recovery Type & 0.89 & Very good \\
Inter-operator & Possession Duration & 0.82 & Very good \\
Inter-operator & Possession Outcome & 0.86 & Very good \\
Intra-operator & Ball Recovery Zone & 0.95 & Very good \\
Intra-operator & Ball Recovery Type & 0.95 & Very good \\
Intra-operator & Possession Duration & 0.86 & Very good \\
Intra-operator & Possession Outcome & 0.93 & Very good \\
\hline
\end{tabular}

to complete the analysis, they were provided with 432 possessions from two matches ( $8.7 \%$ of the full sample). The analyst recorded all of the variables from the investigation for each possession: ball recovery zone; ball recovery type; possession duration; and possession outcome and these were compared to the data collected by the initial observer (first author). The intra-observer test was undertaken one month after the initial data collection process, in order to reduce the likelihood of learning effects (O'Donoghue 2014). The intra-operator reliability test also utilised 432 possessions from two matches and all the variables were recorded. The Kappa statistic test was undertaken for all reliability testing. Tests revealed 'very good' agreement for each variable (Table 3 ).

\section{Data analysis}

Further analysis was conducted within the Statistical Package for the Social Sciences (SPSS) data analysis software (IBM, SPSS Statistics Version 23, Armonk, NY). However, it was observed that the data violated the protocol of the chi-squared $\left(x^{2}\right)$ statistical test of independence undertaken, as too many cells contained an expected value of less than five (McHugh 2013). To offset this, several sub-categories within variables were collapsed and merged together, in order to increase the expected count for the effected cells.

For the ball recovery zone variable, four measures were analysed, comprising of the: 'defence' (including 'left defence', 'centre defence' and right defence'); 'pre-defence' (including 'left pre-defence', 'centre pre-defence' and 'right pre-defence'); 'pre-attack' (including 'left pre-attack', 'centre pre-attack' and 'right pre-attack'); and 'attack' (including 'left attack', 'centre attack' and 'right attack'). The measures for ball recovery type remained the same. The possession duration variable was divided into three measures of ' $<5$ seconds' (including 0s-0.99s', '1s-1.99s', '2s-2.99s', '3s-3.99s' and '4s4.99s), '5-12 seconds' (including '5s-5.99s', '6s-6.99s', '7s7.99s', '8s-8.99s', '9s-9.99s', '10s-10.99s' and '11s-11.99s') and '>12 seconds' (including ' $\geq 12 \mathrm{~s}$ '). Possession outcome was collapsed into five measures: 'goal'; 'shot' (including 'shot on target', 'shot off target' and 'shot blocked'); 'setplay won' (including 'free kick won', 'penalty won' and 'corner won'); 'possession lost due to attacking actions' (including 'misplaced pass/touch', 'offside', 'clearance' and 'foul committed'); and 'possession lost due to defensive actions' (including 'interception - defence', 'tackle defence', 'clearance - defence' and 'goalkeeper claim defence'). 
The chi-square test of independence was undertaken three times, and was layered by competition (EPL and La Liga) each time, in order to identify statistical associations between: (1) ball recovery zones and possession outcomes, (2) ball recovery types and possession outcomes, and (3) possession durations and possession outcomes. The alpha level was placed at 0.05 for each test. Additionally, a Cramer's V test was carried out between the same variables, to identify the size of the association on a scale of 0 (very weak) to 1 (very strong). Standardised residuals (SR) were also calculated which compare the observed value with the expected value for every cell. SR values between -2 and 2 signify little discrepancy, whereas a figure outside this range was considered statistically significant (Agresti 2007).

\section{Results}

From the 20 matches that were analysed, 4971 possessions were observed $(E P L=2469$; La Liga $=2502)$. A total of 55 goals were scored from the 4971 possessions $(1.1 \%$ of possessions led to a goal). In the EPL 33 goals were scored from 2469 possessions (1.3\% of possessions in EPL led to a goal), whilst in La Liga 22 goals were scored from 2502 possessions ( $0.9 \%$ of possessions in La Liga led to a goal).

The chi-square test of association found a significant association between recovery zone and possession outcome in both competitions (EPL: $X^{2}{ }_{(12)}=274.91, p=0.01$; La Liga: $X^{2}$ $\left.{ }_{(12)}=252.33, p=0.01\right)$, with the Cramer's $V$ test displaying a weak effect size (EPL: $V=0.19$; La Liga: $V=0.18$ ). The most frequent locations of ball recovery in both the EPL and La Liga were the defence zone $(E P L=32.4 \%$; La Liga $=31.8 \%)$ and the pre-defence zone (La Liga $=32.4 \%$; EPL $=30.6 \%$ ). There was an over-representation of possessions that were recovered in the attack zone and led to a goal for both the EPL $(S R=4.1)$ and La Liga ( $S R=3.1$ ). A further finding was that there was an overrepresentation of possessions that were recovered in the attack zone and led to a shot for both the EPL $(S R=12.4)$ and La Liga $(S R=11.6)$. There was also an over-representation of possessions that were recovered in the pre-attack zone and led to a shot for both the EPL $(S R=2.0)$ and La Liga $(S R=2.8)$. There was an under-representation of possessions that were recovered in the defence zone and led to a shot for both the EPL $(\mathrm{SR}=-5.3)$ and La Liga (SR $=-6.3)$ (Table 4).

A significant association was also found between ball recovery type and possession outcome in both competitions (EPL: $X^{2}$ ${ }_{(16)}=59.06, p=0.01$; La Liga: $x^{2}{ }_{(16)}=42.58, p=0.01$ ), but with negligible effect sizes identified by the Cramer's $V$ test (EPL: $\mathrm{V}=0.08$; La Liga: $\mathrm{V}=0.07$ ). The most common ball recovery type in the EPL was an interception (30.8\%), whilst set-plays were the most common recovery type in La Liga (29.3\%). There was an over-representation of goals scored from possessions that were recovered from a tackle in La Liga $(S R=2.9)$. There was an under-representation of goals scored from possessions that were recovered from an interception in both the EPL $(S R=-2.2)$ and La Liga $(S R=-2.1)$. There was an overrepresentation of shots taken from possessions that were recovered from a turnover in both the EPL $(S R=4.8)$ and La Liga $(S R=2.6)$ (Table 5).

There was a significant association between possession duration and possession outcome in both competitions (EPL: $X^{2}{ }_{(8)}=40.63, p=0.01 ;$ La Liga: $\left.X^{2}{ }_{(8)}=35.51, p=0.01\right)$, with negligible effect sizes (EPL: $V=0.09$; La Liga: $V=0.08$ ). EPL teams mostly utilise possessions between five and 12 seconds (38.8\% of total EPL possessions), whilst La Liga times mostly utilise possessions that last more than 12 seconds (37.3\% of total La Liga possessions). Teams from the EPL were most efficient at scoring from possessions that lasted under 5 seconds, whilst La Liga teams were most efficient at scoring from possessions over 12 seconds long. There was an overrepresentation of shots taken from possessions that were under 5 seconds in both the EPL $(S R=4.5)$ and La Liga $(S R=2.7)$. There was an under-representation of shots taken from possessions that were $5-12$ seconds in duration in the EPL $(\mathrm{SR}=-3.0)$ (Table 6).

\section{Discussion}

The aim of this study was to explore the impact of the ball recovery type, location of ball recovery and the duration of the

Table 4. Recovery zone and possession outcome for each competition (frequencies, percentages and SRs).

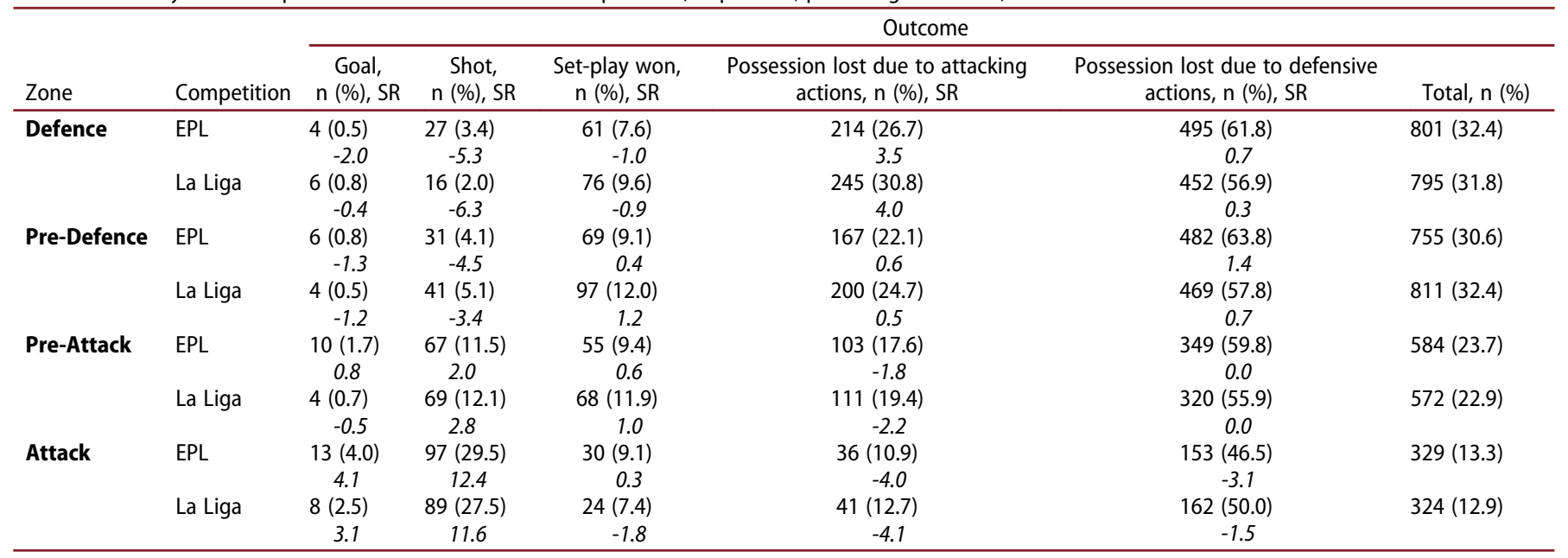


Table 5. Ball recovery type and possession outcome for each competition (frequencies, percentages and SRs).

\begin{tabular}{|c|c|c|c|c|c|c|c|}
\hline \multirow[b]{2}{*}{$\begin{array}{l}\text { Ball recovery } \\
\text { type }\end{array}$} & \multirow[b]{2}{*}{ Competition } & \multicolumn{6}{|c|}{ Outcome } \\
\hline & & $\begin{array}{c}\text { Goal, } \\
\text { n (\%), SR }\end{array}$ & $\begin{array}{l}\text { Shot, } \\
\text { n (\%), SR }\end{array}$ & $\begin{array}{l}\text { Set-play won, } \\
\text { n (\%), SR }\end{array}$ & $\begin{array}{l}\text { Possession lost due to attacking } \\
\text { actions, n (\%), SR }\end{array}$ & $\begin{array}{c}\text { Possession lost due to defensive } \\
\text { actions, } \mathrm{n}(\%), \mathrm{SR}\end{array}$ & Total, n (\%) \\
\hline \multirow[t]{3}{*}{ Interception } & EPL & $3(0.4)$ & $43(5.7)$ & $63(8.3)$ & $180(23.7)$ & $472(62.0)$ & $761(30.8)$ \\
\hline & La Liga & $1(0.1)$ & $48(7.0)$ & 79 (11.5) & $174(25.3)$ & $387(56.2)$ & $689(27.5)$ \\
\hline & & -2.1 & -1.5 & 0.7 & 0.7 & 0.0 & \\
\hline \multirow[t]{2}{*}{ Tackle } & EPL & $5(1.7)$ & $23(7.9)$ & $30(10.3)$ & 66 (22.6) & $168(57.5)$ & $292(11.8)$ \\
\hline & & 0.6 & -0.6 & 0.9 & 0.6 & -0.5 & \\
\hline \multirow{4}{*}{$\begin{array}{l}\text { Goalkeeper } \\
\text { Save }\end{array}$} & EPL & $0(0.0)$ & $4(3.6)$ & $11(10.0)$ & $25(22.7)$ & $70(63.6)$ & $110(4.5)$ \\
\hline & & -1.2 & -1.9 & 0.5 & 0.4 & 0.5 & \\
\hline & La Liga & $0(0.0)$ & $4(3.1)$ & 14 (11.0) & $36(28.3)$ & 73 (57.5) & $127(5.1)$ \\
\hline & & -1.1 & -2.1 & 0.1 & 1.0 & 0.2 & \\
\hline \multirow[t]{3}{*}{ Set-Play } & EPL & $12(1.8)$ & $58(8.7)$ & $50(7.5)$ & $128(19.3)$ & $416(62.7)$ & 664 (26.9) \\
\hline & & 1.0 & -0.2 & -1.0 & -1.0 & 0.9 & \\
\hline & La Liga & $6(0.8)$ & $58(7.9)$ & $69(9.5)$ & $160(21.9)$ & $437(59.9)$ & $730(29.2)$ \\
\hline Turnover & & 0.8 & 2.6 & 0.6 & -1.2 & -0.6 & \\
\hline
\end{tabular}

Table 6. Possession duration and possession outcome (frequencies, percentages and SRs).

\begin{tabular}{|c|c|c|c|c|c|c|c|}
\hline \multirow[b]{2}{*}{$\begin{array}{l}\text { Duration } \\
\text { (s) }\end{array}$} & \multirow[b]{2}{*}{ Competition } & \multicolumn{6}{|c|}{ Outcome } \\
\hline & & $\begin{array}{c}\text { Goal, } \\
\mathrm{n}(\%), \text { SR }\end{array}$ & $\begin{array}{l}\text { Shot, } \\
\mathrm{n}(\%), \text { SR }\end{array}$ & $\begin{array}{l}\text { Set-play won, } \\
\text { n (\%), SR }\end{array}$ & $\begin{array}{l}\text { Possession lost due to attacking } \\
\text { actions, } \mathrm{n}(\%), \mathrm{SR}\end{array}$ & $\begin{array}{l}\text { Possession lost due to defensive } \\
\text { actions, } \mathrm{n}(\%), \mathrm{SR}\end{array}$ & Total, n (\%) \\
\hline \multirow[t]{3}{*}{$<5$} & EPL & $12(2.0)$ & $88(14.4)$ & $51(8.4)$ & $110(18.0)$ & $349(57.2)$ & $610(24.7)$ \\
\hline & La Liga & $8(1.1)$ & 81 (11.6) & 94 (13.4) & $145(20.7)$ & $373(53.2)$ & 701 (28) \\
\hline & & 0.7 & 2.7 & 2.3 & -1.7 & -1.0 & \\
\hline \multirow[t]{2}{*}{$5-12$} & EPL & $7(0.7)$ & $58(6.1)$ & $90(9.4)$ & $221(23.1)$ & $582(60.8)$ & 958 (38.8) \\
\hline & & -1.6 & -3.0 & 0.7 & 1.4 & 0.3 & \\
\hline \multirow[t]{4}{*}{$>12$} & EPL & $14(1.6)$ & $76(8.4)$ & $74(8.2)$ & $189(21.0)$ & $548(60.8)$ & $901(36.5)$ \\
\hline & & 0.6 & -0.6 & -0.5 & -0.1 & -0.4 & \\
\hline & La Liga & $11(1.2)$ & $67(7.2)$ & $85(9.1)$ & $210(22.5)$ & $559(60.0)$ & $932(37.3)$ \\
\hline & & 1.0 & -1.5 & -1.4 & -0.8 & 1.6 & \\
\hline
\end{tabular}

possession on the outcomes of possessions in both the EPL and the Spanish La Liga. There was a significant association between recovery zone and possession outcome in both competitions (EPL: $X^{2}{ }_{(12)}=274.91, p=0.01$; La Liga: $x^{2}{ }_{(12)}=252.33$, $p=0.01$ ), with the Cramer's $V$ test displaying a weak effect size (EPL: $V=0.19$; La Liga: $V=0.18$ ). The most frequent locations of ball recovery in both the EPL and La Liga were the defence zone $(E P L=32.4 \% ;$ La Liga $=31.8 \%)$ and pre-defence zone (La Liga $=32.4 \%$; EPL $=30.6 \%$, highlighting a preference towards recovering the ball closer to their own goal. This could be due to a compact, deep-defending style of defensive play before regaining possession, attempting to win the ball in deeper positions (Low et al. 2018). These results are consistent with those highlighted by both Barreira et al. (2014b) and Almeida et al. (2014), where they both observed possession to be most frequently recovered in the pitch zones positioned closer to the goal that the team is defending.

Most goals in both competitions were scored after recovering ball possession in the attack zone of the pitch $(E P L=4 \%$, SR 4.1; La Liga $=2.5 \%$, SR 3.1), accompanied by a under-representation of shots after possessions started in defence zone $(E P L=3.4 \%$, SR -5.3 ; La Liga $=2 \%$, SR -6.3 ).
Consequently, this data implies that greater attacking success can be achieved by adopting a high-pressing defensive style (Low et al. 2018). This supports the findings of Sarmento et al. (2018) and Hughes and Lovell (2019) who both found a strong relationship between regaining the ball in attacking zones and positive attacking outcomes. Additionally, this is consistent with EPL-specific research, with Wright et al. (2011) reporting that most attacks that culminated in an attempt on goal, derived from central areas within the oppositions half. However, the results of this study oppose the La Liga-specific results of Lago-Ballesteros et al. (2012) who found that the attacks resulting in the most score-box possessions were started in the mid-defensive and mid-attacking zones. It should be noted that this difference might be due to measuring a different determinant of attacking success. There was a significant under-representation of goals scored after possession was recovered in the defence zone in the EPL, with no such finding in La Liga (EPL $=0.5 \%$, SR -2.0 ; La Liga $=0.8 \%$, $S R-0.4)$, suggesting that La Liga teams could be more effective in employing a possession-based playing style and playing out from the back (Lago and Martín 2007). This agrees with Cotta et al. (2013) in which they found that the Spanish 
national team were the most efficient team in possession during the 2010 FIFA World Cup. However, caution is required when comparing the results of international tournament football to domestic competitions (McGarry 2009).

A significant association was also found between ball recovery type and possession outcome in both competitions (EPL: $\mathrm{X}^{2}$ ${ }_{(16)}=59.06, p=0.01$; La Liga: $\left.x^{2}{ }_{(16)}=42.58, p=0.01\right)$, but with negligible effect sizes identified by the Cramer's $V$ test (EPL: $\mathrm{V}=0.08$; La Liga: $\mathrm{V}=0.07)$. The most common ball recovery type in the EPL was an interception (30.8\%), which suggests that EPL teams favour regaining possession through open play. This supports the findings of Oberstone (2011), who discovered that EPL teams make more interceptions than teams in Spain. Set-plays were the most common ball recovery type in La Liga (29.2\%). This may be due to the strictness of La Liga referees, as significantly more free kicks are awarded in Spain (Oberstone 2011). In both competitions, there was a significant underrepresentation of goals scored after an interception $(E P L=0.4 \%, S R-2.2 ;$ La Liga $=0.1 \%$, SR -2.1$)$. This proposes that despite large quantities of interceptions as a type of ball recovery, teams struggle to convert these possessions into goals. This is supported by Hughes and Lovell (2019), who found that only $0.82 \%$ of interceptions result in a goal in the UEFA Champions League. However, they did report that $12.12 \%$ of interceptions result in a shot which is a substantially higher percentage than found within the current study in the EPL (5.7\%) and La Liga (7.0\%). Despite this, Wright et al. (2011) found that a considerably low proportion of shots at goal are preceded by an interception in the EPL, consistent with the results of this present study.

There was an over-representation of goals scored from possessions that were recovered from a tackle in La Liga $(S R=2.9)$, suggesting that La Liga teams can utilise possessions successfully following a tackle. This finding supports research by Barreira et al. (2014b) and Hughes and Lovell (2019), who found that a higher proportion of total tackles result in goals and scoring opportunities than any other ball recovery type. Once again, caution is required when making comparisons as this data comes from FIFA World Cup and UEFA Champions League matches (McGarry 2009). There was an overrepresentation of shots taken from possessions that were recovered from a turnover in both the EPL $(S R=4.8)$ and $L a$ Liga ( $S R=2.6$ ). This implies that teams from both competitions are efficient at capitalising on loose balls after a deflection or rebound. This supports the findings of Wright et al. (2011), who found that the ball recovery type 'other', which is similar to the measure of 'turnover' in this study, accounted for a high proportion of all goals and attempts on goal in their EPL sample. However, caution must be taken with this comparison, as the 'other' variable in Wright et al. (2011) did not include ball recoveries deriving from opponents' errors, which were included in the 'turnover' variable in this current study

There was a significant association between possession duration and possession outcome in both competitions (EPL: $X^{2}{ }_{(8)}=40.63, p=0.01$; La Liga: $\left.X^{2}{ }_{(8)}=35.51, p=0.01\right)$, with a negligible effect size (EPL: $V=0.09$; La Liga: $V=0.08$ ). The most common duration of possessions for EPL teams is between five and 12 seconds (38.8\%), whereas La Liga times more regularly employ possessions that last more than $12 \mathrm{sec}$ onds (37.3\%). This implies that EPL teams prefer a more direct tactical style of play, whereas La Liga teams may prefer a more patient, possession-based style of play (Lago and Martín 2007; Lago 2009). It could be speculated that La Liga players possess more individual quality as they are able to maintain possession for longer periods (Harrop and Nevill 2014). Teams in La Liga had most goal-scoring success when utilising a possession that lasted 12 seconds or more (1.2\%, SR 1.0). This shows that not only do La Liga teams use this possession style of play more frequently but they also use it more successfully than teams in the EPL. This deduction is supported by the findings of LagoBallesteros et al. (2012, which found that more score-box possessions occurred after longer durations in La Liga. This is also in agreement with Tenga and Sigmundstad (2011) that possessions lasting more than 12 seconds produce the most scoring situations in Norwegian football. However, this competition may not be fully comparable, due to the vast difference in technical quality (Tenga et al. 2010b). Conversely, EPL teams score more goals from possessions which last five seconds or less, than teams in La Liga (EPL $=2 \%$, SR 1.3; La Liga $=1.1 \%$, SR 0.7). This could suggest that EPL teams are more effective at implementing a counter-attacking style of play.

Neither competition produced many goals when possessions lasted between five and 12 seconds (La Liga $=0.3 \%$, SR -1.7; $\mathrm{EPL}=0.7 \%$, $\mathrm{SR}-1.6)$, alongside a sizeable underrepresentation of shots in the EPL $(6.1 \%, S R-3.0)$. These findings do not support the research of Smith et al. (2013) who found that the majority of goals are scored when the preceding possession lasted between five and 11 seconds. Some caution is required when interpreting these results as Smith et al. (2013) explored youth and non-league football.

One main limitation of the current study is the onedimensional nature of some of the variables (Mackenzie and Cushion 2013). For example, measuring the occurrence of shots gives an inadequate insight of scoring prospects, as it does not account for specific situational circumstances, such as the distance and angle of the shot (Tenga et al. 2010a). Consequently, the measure of 'goal scored' may remain the only valid measure of success in this study. This is not desirable, due to its extremely low prevalence, placed at approximately $1 \%$ of all possessions (Tenga et al. 2010b). Also, this study does not consider some variables affecting match performance, such as the match location, the match status and the quality of the opponents (Lago 2009). Future research focusing on possession should explore a wider range of variables which may better account for the specific situational context.

The key findings of this study highlighted that both EPL and La Liga teams primarily recovered possession in the defensive zones, but more goals were scored and more shots were taken after recovering the ball in the most advanced attacking zone. La Liga teams achieved more goals after a tackle, whilst EPL teams were more efficient in terms of scoring goals and taking shots following a turnover. As consistent with previous research, EPL teams are more likely to score a goal or create a shooting opportunity when utilising shorter possessions ( $<5$ seconds), whereas La Liga teams are more likely to score a goal after utilising longer possessions ( $>12$ seconds). 


\section{Disclosure statement}

No potential conflict of interest was reported by the authors.

\section{ORCID}

Daniel Cooper (iD http://orcid.org/0000-0002-8755-3489

Craig Pulling (D) http://orcid.org/0000-0003-3941-2021

\section{Practical implications}

To our knowledge, no existing study has previously analysed the relationship between ball recovery patterns and both positive and negative attacking outcomes of possession. Therefore, a wide range of teams and coaches can not only use these findings to help improve their attacking efficiency and goal-scoring prospects, but also to alter their tactics and playing style in order to reduce the chance of negative possession outcomes occurring, and help to decrease the frequency of their team losing ball possession.

\section{References}

Agresti A. 2007. An introduction to categorical data analysis. Hoboken: Wiley.

Almeida CH, Ferreira AP, Volossovitch A. 2014. Effects of match location, match status and quality of opposition on regaining possession in UEFA champions league. J Hum Kinet. 41(1):203-214.

Altman DG. 1991. Practical statistics for medical research. London: Chapman \& Hall.

Armatas V, Yiannakos A. 2010. Analysis and evaluation of goals scored in 2006 World Cup. J Sport Health Res. 2(2):119-128.

Barreira D, Garganta J, Guimarães P, Machado J, Anguera MT. 2014b. Ball recovery patterns as a performance indicator in elite soccer. Proc Inst Mech Eng P J Sport Eng Technol. 228(1):61-72.

Barreira D, Garganta J, Machado J, Anguera MT. 2014a. Effects of ball recovery on top-level soccer attacking patterns of play. Rev Bras Cineantropometria Desempenho Hum. 16(1):36-46.

Bateman R. 2012. BLOG Opta's event definitions. May 12. http://optasports. com/news-area/blog-optas-event-definitions.aspx

Carling C, Williams AM, Reilly T. 2005. Handbook of soccer match analysis: a systematic approach to improving performance. London: Routledge.

Casal CA, Maneiro R, Ardá T, Marí FJ, Losada JL. 2017. Possession zone as a performance indicator in football. The game of the best teams. Front Psychol. 8:1176.

Cotta C, Mora AM, Merelo JJ, Merelo-Molina C. 2013. A network analysis of the 2010 FIFA world cup champion team play. J Syst Sci Complex. 26 (1):21-42.

Eldridge D, Pulling C, Robins MT. 2013. Visual exploratory activity and resultant behavioural analysis of youth midfield soccer players. J Hum Sport Exerc. 8(3):560-577.

Gómez MA, Gómez-Lopez M, Lago C, Sampaio J. 2012. Effects of game location and final outcome on game-related statistics in each zone of the pitch in professional football. Eur J Sport Sci. 12(5):393-398.

Gonzalez-Rodenas J, Lopez-Bondia I, Calabuig F, Pérez-Turpin JA, Aranda R. 2015. The effects of playing tactics on creating scoring opportunities in random matches from US major league soccer. Int J Perform Anal Sport. 15(3):851-872.

Harrop K, Nevill A. 2014. Performance indicators that predict success in an English professional league one soccer team. Int J Perform Anal Sport. 14 (3):907-920.

Hughes M, Lovell T. 2019. Transition to attack in elite soccer. J Hum Sport Exerc. 14(1):236-253.
Kempe M, Vogelbein M, Memmert D, Nopp S. 2014. Possession vs. direct play: evaluating tactical behavior in elite soccer. Int J Sports Sci Coach. 4 $(6 \mathrm{~A}): 35-41$.

Lago C. 2009. The influence of match location, quality of opposition, and match status on possession strategies in professional association football. J Sports Sci. 27(13):1463-1469.

Lago C, Martín R. 2007. Determinants of possession of the ball in soccer. J Sports Sci. 25(9):969-974.

Lago-Ballesteros J, Lago-Peñas C, Rey E. 2012. The effect of playing tactics and situational variables on achieving score-box possessions in a professional soccer team. J Sports Sci. 30(14):1455-1461.

Lago-Peñas C, Dellal A. 2010. Ball possession strategies in elite soccer according to the evolution of the match-score: the influence of situational variables. J Hum Kinet. 25(1):93-100.

Low B, Boas GV, Meyer L, Lizaso E, Hoitz F, Leite N, Gonçalves B. 2018. Exploring the effects of deep-defending vs high-press on footballers' tactical behaviour, physical and physiological performance: a pilot study. Motriz. 24(2):171-177.

Mackenzie R, Cushion C. 2013. Performance analysis in football: a critical review and implications for future research. J Sports Sci. 31(6):639-676.

McGarry T. 2009. Applied and theoretical perspectives of performance analysis in sport: scientific issues and challenges. Int J Perform Anal Sport. 9(1):128-140.

McHugh ML. 2013. The chi-square test of independence. Biochem Med. 23 (2):143-149.

O'Donoghue P. 2014. An introduction to performance analysis of sport. London: Routledge.

Oberstone J. 2011. Comparing team performance of the English Premier League, serie A, and La Liga for the 2008-2009 season. J Quant Anal Sports. 7(1):1-18.

OPTA. 2012. Definitions OPTA and pack training 2012/13. Madrid: OPTA.

Pollard R, Reep C. 1997. Measuring the effectiveness of playing strategies at soccer. J R Stat Soc. 46(4):541-550.

Pulling C, Robins M, Rixon T. 2013. Defending corner kicks: analysis from the English Premier League. Int J Perform Anal Sport. 13(1):135-148.

Rowlinson M, O'Donoghue P. 2008. Performance profiles of soccer players in the 2006 UEFA champions league and the 2006 FIFA World Cup tournaments. In: Reilly T, Korkusuz F, editors. Science and football VI. New York: Routledge; p. 255-260.

Santos P, Lago-Peñas C, García-García O. 2017. The influence of situational variables on defensive positioning in professional soccer. Int J Perform Anal Sport. 17(3):212-219.

Sarmento H, Figueiredo A, Lago-Peñas C, Milanovic Z, Barbosa A, Tadeu P, Bradley PS. 2018. Influence of tactical and situational variables on offensive sequences during elite football matches. J Strength Cond Res. 32 (8):2331-2339.

Shafizadeh M, Gray S, Sproule J, McMorris T. 2012. An exploratory analysis of losing possession in professional soccer. Int J Perform Anal Sport. 12 (1):14-23.

Smith S, Callaway JA, Broomfield AS. 2013. Youth to senior football: a season long case study of goal scoring methods between under 16, under 18 and first team. Int J Perform Anal Sport. 13(2):413-427.

Tenga A, Holme I, Ronglan LT, Bahr R. 2010b. Effect of playing tactics on achieving score-box possessions in a random series of team possessions from Norwegian professional soccer matches. J Sports Sci. 28 (3):245-255.

Tenga A, Ronglan LT, Bahr R. 2010a. Measuring the effectiveness of offensive match-play in professional soccer. Eur J Sport Sci. 10(4):269-277.

Tenga A, Sigmundstad E. 2011. Characteristics of goal-scoring possessions in open play: comparing the top, in-between and bottom teams from professional soccer league. Int J Perform Anal Sport. 11(3):545-552.

Wright C, Atkins S, Polman R, Jones B, Sargeson L. 2011. Factors associated with goals and goal scoring opportunities in professional soccer. Int J Perform Anal Sport. 11(3):438-449. 